\title{
Flexible Hiring Personnel Models to Promote Human Satisfaction and Business Profit for Service Industries
}

\author{
Federico TRIGOS ${ }^{\mathrm{a}, 1}$ and Mario DORIA ${ }^{\mathrm{b}}$ \\ ${ }^{a}$ Tecnologico de Monterrey, EGADE Business School, Monterrey, Mexico \\ ${ }^{\mathrm{b}}$ Universidad Iberoamericana, Mexico City, Mexico
}

\begin{abstract}
In service industries personnel performance is key to achieve business excellence. Until recently, forty to forty eight hours per week labor contracts with equal daily schedules (eight hours per day) was the only way formal employees were hired in some countries. Recently, this trend has changed and some countries started to allow work contracts with less weekly hours and flexible daily schedules. This offers some degrees of freedom to employees to work less than eight hours per day and non-necessarily having the same timetable every workday. The fabric of society is impacted since now work is at reach for many people who cannot work full time schedules for diverse reasons. The contribution of this work is a Transdisciplinary Flextime Hiring Method that considers both employee and company needs. Using organisational design concepts (business management), flexibility is analysed through integer programming modelling (engineering optimisation) to evaluate cost changes resulting from implementing flextime (societal needs). Service companies may justify and implement flextime based on cost reductions, along with its associated improvement of employee satisfaction and commitment. Numerical analysis based on industry data illustrates these concepts and consequences.
\end{abstract}

Keywords. flextime, integer programming, company culture, transdisciplinary, workforce satisfaction

\section{Introduction}

Businesses are always searching for ways to improve their operational efficiency, where flexible organizational structures are specially relevant for satisfactory goal-achievement simultaneous with lowest total cost.

As companies struggled to increase efficiency by focusing on the control of variability, competition for customers and talent in the XXI century has shifted the focus to innovation and flexibility [1]. In this context, flexibility is interpreted as the firm's ability to add or remove scarce and costly resources, with an emphasis on employees hired for their knowledge and competences to do useful work under a controlled regulatory environment.

This flexibilization of the workforce has an increasing presence in organizational design [2], based on increasing competitiveness pressures, labor market fluctuations, product innovation and adoption of new technologies $[2,3]$.

\footnotetext{
${ }^{1}$ Corresponding Author, Mail: ftrigos@tec.mx.
} 
However, legal regulations in most of the world force rigid labor contracts, resulting in fixed procedures that, at least, hinder flexibility. Employees, on their part, increasingly search for opportunities to confront and resolve work and non-work demands [4].

Under systemic disruptions, such as the Black Swan phenomena of the COVID pandemic, company's resilience is under pressure. Thus, operational practices should adopt changes to recover sustainability. For service organisations, there is an opportunity to hire more people under limited hours of working days, or less working days, to increase operational efficiency without losing service quality, while offering part-time jobs to persons in need.

Transdisciplinary engineering offers a suitable methodology to tackle this complex problem. From Ertas [5] "Transdiciplinarity is a development of new ... tools \& technologies shared by researchers from different family of disciplines (Social science, natural science, humanities and engineering)". Furthermore the International Society of Transdisciplinary Engineering (ISTE) [6] states that it "is a methodological approach, explicitly incorporating social sciences to gather information and to guide implementation of engineering solutions in practice" and deepens the concept with "To create engineering solutions that minimise ... societal damage, engineering design and practices must involve people with the necessary knowledge and methods to determine the impact of new products and services, not only on client and user satisfaction, but also on long-term sustainability." [7].

In this work, authors present a transdisciplinary approach (engineering optimisation, business organizational design and social job opportunities for minorities) to the problem of meeting company's need for satisfactory service over long workdays versus employee's life balance needs, affecting their motivation and concentration.

By using a mathematical model designed for cost optimization and applying it to allow for the implementation of flextime, one can explore cost implications of hiring under a number of scheduling options to achieve a supportive culture, sensitive to employee's needs. Thus, improving economic efficiency and increasing job satisfaction and retention.

The contribution of this work is a Transdisciplinary Flextime Hiring Method (TFHM) that considers both employee and company needs. Using organisational design concepts (business management), flexibility is analysed through integer programming modelling (engineering optimisation) to evaluate cost changes resulting from implementing flextime (societal needs). Service companies may justify and implement flextime based on cost reductions, along with its associated improvement of employee satisfaction and commitment.

This paper is organized as follows: in Section 1 the flexible time imperative is analysed in studies in organisational behavior and psychology, from both the employee's and company's viewpoint; Section 2 presents a transdisciplinary method to implement flextime and analyse its consequences in cost; and Section 3 shows a numerical instance in a service company, based on industry data, with analysis of results and consequences.

\section{Flexible time}

Flexible Working Arrangements (FWA) are "mutually beneficial arrangements between employers and employees in which both parties agree on when, and how the employee will work to meet the firm's needs" [8]. Flextime is the arrangement over time, when the workday begins and ends, more working hours over less week days or part-time work. 
Flexibility may also be in performed functions: job enrichment or multi-purpose contracts based on employee's capabilities and pre-existing skill enhancement, that have been found to be perceived as a favourable influence to stay in the firm $[2,9,10]$.

To analyse flextime, both viewpoints are explored, as they are different: the employee's and the company's.

\subsection{From the employee's view}

FWA offers employees some degree of control over the context on which they work [4], they find them attractive based on their perceived signal that the company cares about them [11] and is more supportive [12, 13]. FWA have a strong effect on work interference with family life [14] and decreased work-family conflict [15] and are perceived as providers of job satisfaction [16], commitment to the organization, productivity [17] and decreased absenteeism [18].

A desired effect of non-traditional flextime is that workers are more able to find a better balance between working hours and personal time, enhanced autonomy and intensification of work commitment [19]. By having more say in their working hours, they may find a better fit of their working and personal lives $[2,20]$.

Employees that perceive their schedules as flexible, reported higher levels of workpersonal life balance and paths to well-being [21], consistent with current theories on effects of organizational culture's effect on happiness and less stressed lives.

\subsection{From the company's view}

An organization's competitive advantage is often based on specific knowledge residing on its employees [22], it is crucial to attract the most talented people and manage to retain them. As more and more companies manage their human capital strategically, in times of talent shortage [23], being perceived as family-friendly helps attract and retain qualified talent [17]

Flexibility is no longer a perk but a competitive tool to meet recruitment objectives, FWA facilitate the creation of people-based competitive advantages [8,24]. The creation of a supportive culture means the company is sensitive to employee's family needs and does not demand prioritization of work over family [21].

From a transdisciplinary approach, cost optimisation must be considered. Academic literature offers scant treatment of this crucial combination of economic optimization and strategic talent attraction and retaining.

\subsection{A case in point: women in the workforce}

The increased participation of women in the workforce has a profound impact on family's decisions over childbearing and home division of labor and income [25]. Women have chosen new life roles, their compatibility with work-family equilibrium have been found to be a relevant driving force behind fertility decreases in industrialized countries [26, 27].

Women who also work outside their home, face barriers to advance within corporate structures, one of such is the difficult balance of work and family responsibilities [28]. Some choose to delay work advancement while children need their concentration. 
If the opportunity is offered to have a flexible work schedule, the probability that competent, career-oriented women will remain at work may increase [17], to the benefit of the woman, her family and the company.

\section{Flextime transdisciplinary implementation method}

Implementing a flextime arrangement in a service-oriented company, where core activities are performed through direct intervention of qualified employees, is a complex task that we aim to simplify.

While research on the impact of flexible time focus on firm or employee's performance and job satisfaction, it does not address the complex issues in managing its implementation; at the same time, operations research offers solutions for workforce scheduling but do not address the flexibility needed by workers and its regulatory restrictions. Thus our transdisciplinary approach.

Organizations under analysis require positions staffed under regulatory restrictions of daily working hours, without missing a single moment to service the customer, every day for 12,14 or longer working days, as is the case of many service establishments such as convenience, department or grocery stores, bank tellers, cinema theaters, call centers, service stations (like fuel dispensing), parking or toll-booth attendants, or hotel reception desks, to name a few.

\subsection{The Transdisciplinary Flextime Hiring Method}

Mohamad and Said [29] started with the daily service capacity requirements (servers in each time slot) [30], known in operations research as the Toll-Booth Problem. In many applications, number of servers was observed to vary daily. Later, Trigos, Vazquez and Cárdenas-Barrón [31] developed a simulation-based heuristic to define daily service capacity requirements to guarantee specific quality performance indicators.

Many service companies require different daily server capacities throughout the week. Using Trigos, Vazquez and Cárdenas-Barrón [31] methodology for each weekday, a full-week daily server requirements can be obtained, namely the Weekly Service Capacity Matrix (WSCM).

Table 1 presents the TFHM steps.

Table 1. Steps of TFHM.

\begin{tabular}{|c|l|l|}
\hline Step & Activity & Comments \\
\hline 1 & $\begin{array}{l}\text { Define the Week } \\
\text { Service Capacity } \\
\text { Matrix (WSCM). }\end{array}$ & $\begin{array}{l}\text { Specify a service capacity matrix form, which defines the minimum } \\
\text { number of servers per day and time slot (from opening to closing, hour } \\
\text { by hour and day by day) to achieve the desired service performance } \\
\text { indicator. } \\
\text { One option is to use [28] for every day of the week. }\end{array}$ \\
\hline 2 & Define working days & 6 days in a row, or single-day are examples to consider. \\
\hline 3 & $\begin{array}{l}\text { Define hours of } \\
\text { working days } \\
\text { (possible work } \\
\text { schedules for each } \\
\text { day). }\end{array}$ & $\begin{array}{l}\text { 8,6 or 4 working hours plus lunchtime allowance are examples to } \\
\text { consider. }\end{array}$ \\
\hline 4 & $\begin{array}{l}\text { Set the integer } \\
\text { programming model }\end{array}$ & $\begin{array}{l}\text { The goal (the objective function) is to minimize total payroll by } \\
\text { determining the working contracts. } \\
\text { The constraints to be satisfied are defined per day and time period } \\
\text { (time slot), the number of attendants present in each slot must be at } \\
\text { least those defined in the WSCM. }\end{array}$ \\
\hline
\end{tabular}




\begin{tabular}{|c|c|c|}
\hline Step & Activity & Comments \\
\hline & & $\begin{array}{l}\text { The model variable is the number of contracts (people to be hired) for } \\
\text { each combination of hours-of-working-days and working-days }\end{array}$ \\
\hline 5 & Model execution & $\begin{array}{l}\text { Several commercial software options are available, among them: the } \\
\text { General Algebraic Modelling System }{ }^{\circledR} \text { (GAMS), LINGO }{ }^{\circledR} \text { or MS } \\
\text { Excel Solver }^{\circledR} \text {. }\end{array}$ \\
\hline 6 & Scenario analysis & $\begin{array}{l}\text { Analyse different scenarios by modifying hours of working days } \\
\text { and/or working days to explore as many possibilites as can be } \\
\text { imagined. }\end{array}$ \\
\hline 7 & $\begin{array}{l}\text { Prepare the } \\
\text { comparison table }\end{array}$ & $\begin{array}{l}\text { To visualise all the options analysed and select the optimal for the } \\
\text { company. }\end{array}$ \\
\hline 8 & $\begin{array}{l}\text { Allocate people to } \\
\text { contracts }\end{array}$ & $\begin{array}{l}\text { Each candidate selects preferred non-overlapping available contracts. } \\
\text { Company may allot the most sought-after slots to the best candidates, } \\
\text { based on past performance, commitment and other criteria. }\end{array}$ \\
\hline
\end{tabular}

The goal for the company is to meet those requirements with minimum payroll cost by way of flextime hiring.

A contract is meant as a commitment between one person and the company to perform work during a specified period (the contract schedule), in exchange for payment.

There are three concepts to have in mind: Contracts (determined by the combination of the variable indexes), Weekly-contract-equivalent (WCE) (a contract to work six days per week eight hours per day), and headcount (number of individuals working in the system); the latter cannot be directly determined, since an individual could work on several contracts as long as none of them overlap. This opens the door for multiple ways to hire individuals, for instance an individual could sign one contract for 9:00 to 13:00 and another from 15:00 to 16:00, and only on Mondays.

\subsection{A numerical example}

Let us analyze a particular service company (a large grocery store, for instance) that works seven days per week, twelve hours per day. Service quality analysis defines that for the next season, the number of open cashiers per working hour and day of the week must satisfy the minimum requirements shown in Table 2 (TFHM Step 1).

Table 2. WSCM for the numerical example.

\begin{tabular}{rccccccc}
\hline \multirow{2}{*}{$\begin{array}{c}\text { Start } \\
\text { time }\end{array}$} & \multicolumn{7}{c}{ Minimum number of open cashiers needed } \\
\cline { 2 - 7 } & Monday & Tuesday & Wednesday & Thursday & Friday & Saturday & Sunday \\
\hline 9:00 & 6 & 5 & 5 & 4 & 4 & 5 & 5 \\
$10: 00$ & 7 & 6 & 5 & 5 & 5 & 6 & 6 \\
$11: 00$ & 7 & 6 & 5 & 6 & 5 & 8 & 7 \\
$12: 00$ & 7 & 6 & 5 & 5 & 5 & 7 & 7 \\
$13: 00$ & 7 & 6 & 5 & 5 & 5 & 7 & 7 \\
$14: 00$ & 7 & 5 & 5 & 5 & 6 & 9 & 8 \\
$15: 00$ & 7 & 6 & 6 & 5 & 6 & 9 & 7 \\
$16: 00$ & 8 & 6 & 6 & 6 & 6 & 9 & 7 \\
$17: 00$ & 8 & 6 & 6 & 6 & 7 & 10 & 8 \\
$18: 00$ & 9 & 7 & 7 & 7 & 7 & 10 & 10 \\
$19: 00$ & 10 & 7 & 8 & 6 & 8 & 10 & 9 \\
\hline
\end{tabular}

Company defines that it can accept that people sign-in for 6-day or single-day commitments, as shown in Table 3 (TFHM Step 2), and acceptable hours of working days are as in Table 4 (TFHM Step 3).

Management is used only to full-week contract hiring but is willing to explore new options using the WCE concept to compare final cost.

In this example, company's hourly wage rate is constant, independent of time of day or weekday. Thus, minimising total sum of working hours is equivalent to minimising 
payroll. Since 48 hours of work determines a WCE, minimising total WCEs is also equivalent to minimising payroll and thus cost.

TFHM Step 4: The integer programming model was run under GAMS ${ }^{\circledR} 33.2 .0$ using Cplex 12.10.0.0 with up to 378 contract variables (14 working days times 27 hours of working days), 84 restrictions ( 7 workdays times 12 working hours per day). Four scenarios were analysed, each one took neglible processing time on a MacBook Air computer running under MacOS Big Sur 11.2.1, having 2.2 GHz Dual-Core Intel Core i7 processor and 8GB RAM.

Four scenarios were defined for analysis: current practice and three of increased flexibility (TFHM Steps 5 and 6), described as follows.

Table 3. Working days.

\begin{tabular}{clcl}
\hline Period & Description & Period & Description \\
\hline Mo_Sa & Monday to Saturday & Mo & Monday \\
Tu_Su & Tuesday to Sunday & Tu & Tuesday \\
We_Mo & Wednesday to Monday & We & Wednesday \\
Th_Tu & Thursday to Tuesday & $\mathrm{Th}$ & Thursday \\
Fr_We & Friday to Wednesday & $\mathrm{Fr}$ & Friday \\
Sa_Th & Saturday to Thursday & $\mathrm{Sa}$ & Saturday \\
$\mathrm{Su}$. Fr & Sunday to Friday & $\mathrm{Su}$ & Sunday \\
\hline
\end{tabular}

Table 4. Hours of working days

\begin{tabular}{ccc}
\hline $\mathbf{8}$ hours per day & 6 hours per day & 4 hours per day \\
\hline 9 to 12 and 13 to 18 & 9 to 12 and 13 to 16 & 9 to 13 \\
9 to 13 and 14 to 19 & 10 to 13 and 14 to 17 & 10 to 14 \\
9 to 14 and 15 to 18 & 11 to 14 and 15 to 18 & 11 to 15 \\
10 to 13 and 14 to 19 & 12 to 15 and 16 to 19 & 12 to 16 \\
10 to 14 and 15 to 19 & 13 to 16 and 17 to 20 & 13 to 17 \\
10 to 15 and 16 to 19 & 14 to 17 and 18 to 21 & 14 to 18 \\
11 to 14 and 15 to 20 & & 15 to 19 \\
11 to 15 and 16 to 20 & & 16 to 20 \\
11 to 16 and 17 to 20 & & 17 to 21 \\
12 to 15 and 16 to 21 & & \\
12 to 16 and 17 to 21 & & \\
12 to 17 and 18 to 21 & & \\
\hline
\end{tabular}

\section{Scenario 1}

Only contracts for six 8 hours of working days are allowed, i.e. everybody works full time as it is currently practiced. Table 5 presents contract assignments, the last row shows WCEs for each assigned working days, with a sum of 17 WCEs for this scenario.

Table 5. Optimal solution for scenario 1, 17 WCEs. Only full week contracts are considered.

\begin{tabular}{|c|c|c|c|c|c|c|c|}
\hline \multirow[t]{2}{*}{ Hours of working days } & \multirow{2}{*}{$\begin{array}{l}\text { Hours } \\
\text { per day }\end{array}$} & \multirow[b]{2}{*}{ Mo_Sa } & \multirow[b]{2}{*}{ We_Mo } & \multicolumn{2}{|c|}{ Working days } & \multirow[b]{2}{*}{ Sa_Th } & \multirow[b]{2}{*}{ Su_Fr } \\
\hline & & & & Th_Tu & Fr_We & & \\
\hline 9 to 14 and 15 to 18 & 8 & 1 & & & 2 & 2 & 1 \\
\hline 10 to 13 and 14 to 19 & 8 & & & 1 & & & \\
\hline 11 to 15 and 16 to 20 & 8 & & & & 1 & & \\
\hline 11 to 16 and 17 to 20 & 8 & & & 1 & & & \\
\hline 12 to 15 and 16 to 21 & 8 & 1 & 2 & & & 2 & \\
\hline 12 to 16 and 17 to 21 & 8 & & & 1 & 2 & & \\
\hline Daily worked hours & & 16 & 16 & 24 & 40 & 32 & 8 \\
\hline Workdays & & 6 & 6 & 6 & 6 & 6 & 6 \\
\hline Week hours & & 96 & 96 & 144 & 240 & 192 & 48 \\
\hline WCEs & & 2 & 2 & 3 & 5 & 4 & 1 \\
\hline
\end{tabular}

\section{Scenario 2}

Only one working day contracts with 4, 6 and 8 possible hours of working days are available. An employee could be hired for more than one contract, if they do not overlap. 
The minimum WCEs are $16+1 / 3$. The particular contracts are shown in Table 6 . Notice that in this particular instance, only 8 -hour days were selected.

Table 6. Optimal solution for scenario $2,16+1 / 3$ WCEs. Only one day contracts are considered.

\begin{tabular}{lcccccccc}
\hline Hours of working days & $\begin{array}{c}\text { Hours } \\
\text { per day }\end{array}$ & Mo & Tu & We & Th & Fr & Sa & Su \\
\hline 9 to 12 and 13 to 18 & 8 & 6 & & & & 4 & & \\
9 to 13 and 14 to 18 & 8 & & 5 & 5 & & & & \\
9 to 14 and 15 to 18 & 8 & & & & 4 & & 5 & 5 \\
10 to 14 and 15 to 19 & 8 & & & & & & 1 & 1 \\
10 to 15 and 16 to 19 & 8 & 1 & 1 & & 1 & 1 & & \\
11 to 14 and 15 to 20 & 8 & & 1 & & & & & 1 \\
11 to 15 and 16 to 20 & 8 & 1 & & 2 & & 2 & & \\
11 to 16 and 17 to 20 & 8 & 1 & & & 1 & & 2 & \\
12 to 15 and 16 to 21 & 8 & 8 & 6 & & 5 & & 7 & 8 \\
12 to 16 and 17 to 21 & 8 & & & 6 & & 6 & 1 & \\
Daily worked hours & & 136 & 104 & 104 & 88 & 104 & 128 & 120 \\
Workdays & & 1 & 1 & 1 & 1 & 1 & 1 & 1 \\
Week hours & & $2+56$ & 104 & 104 & 88 & 104 & 128 & 120 \\
WCEs & & & & & & & & \\
\hline
\end{tabular}

Scenario 3

Six working day contracts are mandatory but 4,6 , and 8 hours of working days are feasible. The minimum WCEs are $12+1 / 2$. The particular contracts are shown in Table 7.

Table 7. Optimal solution for scenario $3,12+1 / 2$ WCEs. Six-day contracts are mandatory.

\begin{tabular}{|c|c|c|c|c|c|}
\hline \multirow[t]{2}{*}{ Hours of working days } & \multirow{2}{*}{$\begin{array}{l}\text { Hours } \\
\text { per day }\end{array}$} & \multicolumn{4}{|c|}{ Working days } \\
\hline & & We_Mo & Th_Tu & Fr_We & Sa_Th \\
\hline 9 to 12 and 13 to 18 & 8 & & & 1 & \\
\hline 9 to 14 and 15 to 18 & 8 & & & & 1 \\
\hline 9 to 12 and 13 to 16 & 6 & & 1 & & \\
\hline 10 to 13 and 14 to 17 & 6 & & 1 & & \\
\hline 14 to 17 and 18 to 21 & 6 & & & 2 & \\
\hline 9 to 13 & 4 & 1 & & 1 & 1 \\
\hline 11 to 15 & 4 & & 1 & & \\
\hline 12 to 16 & 4 & & & 1 & \\
\hline 13 to 17 & 4 & 1 & & & 1 \\
\hline 16 to 20 & 4 & 2 & & & \\
\hline 17 to 21 & 4 & 1 & 2 & 1 & 2 \\
\hline Daily worked hours & & 20 & 24 & 32 & 24 \\
\hline Workdays & & 6 & 6 & 6 & 6 \\
\hline Week hours & & 120 & 144 & 192 & 144 \\
\hline WCEs & & $2+1 / 2$ & 3 & 4 & 3 \\
\hline
\end{tabular}

\section{Scenario 4}

Either six- or one-working day contracts are feasible along with 4, 6 or 8 hours of working days. The minimum WCEs are $11+5 / 8$. The particular contracts are shown in Table 8 . Notice that only one-day contracts were selected in the solution.

\section{Scenario comparison}

With Scenario 1 as the reference, Table 9 presents comparative results (TFHM Step 7). As flexibility increases, less WCEs are required, thus payroll decreases significantly without any loss in attendant availability.

Increasing flexibility to allow for variable-length working hours is an advantage for part-time candidates, for example women rising children or elders, and at the same time results show an important reduction in payroll. In addition, less continuous time in front of customers may aid in improving quality of service, as attendants are less tired. This particular effect is a topic for further research. 
The strongest impacts are found in scenarios 3 and 4, with the adoption of more flexibility. Since the company is used to everybody having the same schedule, it is recommended to attempt Scenario 3 first, gain experience, and then embark on full flexibility (Scenario 4), while carefully observing the changes in employee's performance, satisfaction and commitment, as measures of a better personal-work life balance.

TFHM Step 8 corresponds to company decisions based on the previous comparison, not included as it is proprietary information.

\section{Conclusions}

Flextime is possible and economically viable for the company and beneficial to the employee. From the company's viewpoint, it can be implemented with a significant cost reductions, with the additional advantage of improved work climate and employee commitment.

Since headcount depends on the number of contracts an individual takes (as long as they do not overlap), individual-contract assignment can take a number of forms such as: a) Minimize headcount (to reduce personnel control difficulty); b) Assignment by individual performance measure, i.e. the employee with best performance in the previous planning period gets to select the contracts he/she will take first, and so on. This promotes motivation for individual performance.

Table 8. Optimal solution for scenario 4, 11+5/8 WCEs. Full flexibility.

\begin{tabular}{|c|c|c|c|c|c|c|c|c|}
\hline \multirow{2}{*}{$\begin{array}{l}\text { Hours of working } \\
\text { days }\end{array}$} & \multirow{2}{*}{$\begin{array}{c}\text { Hours } \\
\text { per } \\
\text { day }\end{array}$} & \multicolumn{7}{|c|}{ Working days } \\
\hline & & Mo & $\mathbf{T u}$ & We & Th & $\mathbf{F r}$ & Sa & $\mathrm{Su}$ \\
\hline 9 to 12 and 13 to 18 & 8 & & 1 & & & & & \\
\hline 9 to 14 and 15 to 18 & 8 & 1 & 1 & 1 & & & & \\
\hline 10 to 13 and 14 to 19 & 8 & & & & & & & 1 \\
\hline 11 to 14 and 15 to 20 & 8 & & & & & & 1 & \\
\hline 12 to 15 and 16 to 21 & 8 & 1 & & & & 1 & 2 & \\
\hline 12 to 17 and 18 to 21 & 8 & 1 & 2 & 2 & & & & 2 \\
\hline 9 to 12 and 13 to 16 & 6 & 2 & 1 & 2 & & 2 & 3 & 2 \\
\hline 10 to 13 and 14 to 17 & 6 & & & & & & 1 & \\
\hline 11 to 14 and 15 to 18 & 6 & & & & & & 1 & \\
\hline 14 to 17 and 18 to 21 & 6 & 2 & 1 & 1 & 1 & 2 & 2 & \\
\hline 9 to 13 & 4 & 3 & 2 & 2 & 4 & 2 & 2 & 3 \\
\hline 10 to 14 & 4 & 1 & 1 & & 1 & 1 & & \\
\hline 11 to 15 & 4 & & & & 1 & & & 1 \\
\hline 12 to 16 & 4 & & & & & 1 & & \\
\hline 13 to 17 & 4 & 1 & & & 3 & & & 2 \\
\hline 14 to 18 & 4 & & & & & 1 & 1 & \\
\hline 15 to 19 & 4 & & & & 1 & & & \\
\hline 16 to 20 & 4 & 2 & 1 & 2 & 1 & 2 & 1 & 2 \\
\hline 17 to 21 & 4 & 4 & 3 & 3 & 4 & 3 & 4 & 5 \\
\hline Daily worked hours & & 92 & 72 & 70 & 66 & 72 & 98 & 88 \\
\hline Workdays & & 1 & 1 & 1 & 1 & 1 & 1 & 1 \\
\hline Week hours & & 92 & 72 & 70 & 66 & 72 & 98 & 88 \\
\hline WCEs & & $1+11 / 12$ & $1+1 / 2$ & $1+11 / 24$ & $1+3 / 8$ & $1+1 / 2$ & $2+1 / 24$ & $1+5 / 6$ \\
\hline
\end{tabular}

From the employee's viewpoint, the opportunity of working part-time, in 4- or 6hour blocks, allows other family or personal activities. This opens the door to hire: students, women raising children, caregivers and other population segments who need to work but do not have the option of a full schedule. 
Table 9. Comparison of results.

\begin{tabular}{lcc}
\hline & WCEs & $\begin{array}{c}\text { Payroll } \\
\text { savings }\end{array}$ \\
\cline { 2 - 3 } Scenario 1 (reference) & 17 & \\
Scenario 2 (one-day contracts) & $16+1 / 3$ & $3.92 \%$ \\
Scenario 3 (4, 6 or 8-hour schedules) & $12+1 / 2$ & $26.47 \%$ \\
Scenario 4 (full flexibility) & $11+5 / 8$ & $31.62 \%$ \\
\hline
\end{tabular}

Under systemic disruptions, company's resilience may improve by hiring people under limited hours of working days, or less working days, thus increasing operational efficiency without losing service quality.

Some of the challenges involved are: a) a larger number of persons in payroll increases control complexity, although this is manageable by modern information technology solutions; b) Supervision is more difficult as servers may change constantly; and c) It is a change in paradigm for managers both in operations and in people management.

Even though the mathematical model presented in the numerical example assumed equal hourly payment regardless of the hour and the day of the week, the model could be easily adapted to include different rates according to time and weekdays, like Sundays or third shifts.

\section{Further research}

Further research pends ahead: a) to analyze a larger number of sets (hours per day and hours per working day) depending on particular industries; b) transversal studies on the social impact of implementing these flextime solutions, including effects on family life, job satisfaction or other; c) feasibility of flexible labor laws, where such part-time jobs are not accepted.

\section{References}

[1] A. Seers, Leadership and flexible organizations: Organizational structures, In G. B. Graen (ed.) New Frontiers of Leadership, Information Age Publishing, Greenwich, CT, 2004, pp. 1.

[2] M. F. J. Martens, F. J. N. Nijhuis, V. B. M. P. J. and J. A. Knottnerus. Flexible Work Schedules and Mental and Physical Health. A Study of a Working Population with Non-Traditional Working Hours. Journal of Organizational Behavior, Vol. 20, 1999, pp. 35.

[3] H. Boekraad, W. Buitelaar and R. Vreeman. Van arbeidsproces naar arbeidsbeleid (From labour process to labour policy). Te Elfder Ure, Vol. 4, 1988, pp. 6.

[4] R. J. Thompson, S. C. Payne and A. B. Taylor. Applicant attraction to flexible work arrangements: Separating the influence of flextime and flexplace. Journal of Occupational \& Organizational Psychology, Vol. 88, 2015, pp. 726.

[5] A. Ertas. Understanding of Transdiscipline and Transdisciplinary process. Transdisciplinary Journal of Engineering \& Science, Vol. 1, 2010, pp. 48.

[6] N. Wognum, C. Bil, F. Elgh, M. Peruzzini, J. Stjepandić, W. Verhagen, Transdisciplinary engineering research challenges, Advances in Transdisciplinary Engineering, 2018, Vol. 7, pp. 753-762.

[7] S. Lattanzio, et al., Transdisciplinarity Within the Academic Engineering Literature, International Journal of Agile Systems and Management, 2020, Vol. 13(2), pp. 213-232.

[8] E.E. Kossek, L.B. Hammer, T. Thompson and L.B. Burke, Leveraging Workplace Flexibility for Engagement and Productivity, SHRM Foundation, 2014.

[9] F.J.N. Nijhuis, M.L.H.G. Lendfers and R. Bullinga. Health effects of flexibilisation of work. News from EFPPA, Vol. IV, 1990, pp. 11-14.

[10] H. W. TenDam. Managerial Flexibility: A Strategic Asset. Leadership \& Organization Development Journal, Vol. 8, 1987, pp. 11-16. 
[11] S. L. Grover and K. J. Crooker. Who appreciates family-responsive human resource policies: The impact of family-friendly policies on the organizational attachment of parents and non-parents. Personnel Psychology, Vol. 48, 1995, pp. 271-288.

[12] W. J. Casper and L. C. Buffardi. Work-life benefits and job pursuit intentions: The role of anticipated organizational support. Journal of Vocational Behavior, Vol. 65, 2004, pp. 391-410.

[13] L. Rhoades and R. Eisenberger. Perceived organizational support: A review of the literature. Journal of Applied Psychology, Vol. 87, 2002, pp. 698-714.

[14] T.D. Allen, R.C. Johnson, K.M. Kiburz and K.M. Shockley, Work-Family Conflict and Flexible Work Arrangements: Deconstructing Flexibility, Personnel Psychology, 2013, Vol. 66(2), pp. 345-376.

[15] J. A. Meyer, Examining workplace flexibility across work and family domains, $\mathrm{PhD}$ thesis, University of Tulsa, 1997.

[16] B. B. Baltes, T. E. Briggs, J. W. Huff, J. A. Wright and G. A. Neuman. Flexible and compressed workweek schedules: A meta-analysis of their effects on work-related criteria. Journal of Applied Psychology, 1999, Vol. 84, pp. 496-513.

[17] S. A. Rogier and M. Y. Padgett. The Impact of Utilizing a Flexible Work Schedule on the Perceived Career Advancement Potential of Women. Human Resource Development Quarterly, 2004, Vol. 15, pp. 89-106.

[18] J. Pierce, J. Newstrom, R. Dunham and A. Barber, Alternative work schedules, Allyn \& Bacon, Boston, 1989.

[19] C. L. ter Hoeven and W. van Zoonen. Flexible work designs and employee well-being: Examining the effects of resources and demands. New Technology, Work and Employment, 2015, Vol. 30, pp. 237255.

[20] D. T. Hall and V. A. Parker. The role of workplace flexibility in managing diversity. Organizational Dynamics, 1993, Vol. 22, pp. 5-18.

[21] J. Soo Jung. The Relationships of Flexible Work Schedules, Workplace Support, Supervisory Support, Work-Life Balance, and the Well-Being of Working Parents. Journal of social service research, 2009, Vol. 35, pp. 93-104.

[22] J. Badaracco, The Knowledge Link: How Firms Compete Through Strategic Alliances, The Free Press, Boston, 1990.

[23] G. Onken-Menke, S. Nüesch and C. Kröll. Are you attracted? Do you remain? Meta-analytic evidence on flexible work practices. Business Research, 2018, Vol. 11, pp. 239-277.

[24] J. Barney. Firm resources and sustained competitive advantage. Journal of Management, 1991, Vol. 17, pp. 99-120.

[25] K. Begall, M. Mills and H.B.G. Ganzeboom, Non-Standard Work Schedules and Childbearing in the Netherlands: A Mixed-Method Couple Analysis. Social Forces, 2015, Vol. 93, pp. 957-988.

[26] N. Balbo, F. C. Billari and M. Mills. Fertility in Advanced Societies: A Review of Research. European Journal of Population / Revue européenne de Démographie, 2013, Vol. 29, pp. 1-38.

[27] K. L. Brewster and R. R. Rindfuss. Fertility and Women's Employment in Industrialized Nations. Annual Review of Sociology, 2000, Vol. 26, pp. 271-296.

[28] K. M. Collins. Stress and departures from the public accounting profession: A study of gender differences. Accounting Horizons, 1993, Vol. 7, pp. 29-38.

[29] N. H. Mohamad and F. Said. Integer Linear Programming Approach to Scheduling Toll Booth Collectors Problem. Indian Journal of Science and Technology, 2013, Vol. 6, No. 5, pp. 1-6.

[30] H. E. Miller. Personnel scheduling in public systems: a survey. Socio-Economic Planning Sciences, 1976, Vol. 10, pp. 241-249.

[31] F. Trigos, A. R. Vazquez and L. E. Cárdenas-Barrón. A simulation-based heuristic that promotes business profit while increasing the perceived quality of service industries. International Journal of Production Economics, 2019, Vol. 211, pp. 60-70. 